\title{
Analysis of Competition between Radio \& TV and Network Media
}

\author{
Jiong Xu \\ Qianjiang College, Hangzhou, 310015, China
}

\begin{abstract}
This paper mainly discusses about competitive integration relationship between network media and traditional media with representative of radio \& TV, i.e. firstly analyzes their respective advantages and disadvantages, and points out that new media which mainly include network media and traditional media which mainly include radio \& TV shall complement each other's advantages and have competitive integration to enhance advantages and avoid disadvantages, so that traditional media such as radio \& TV etc could realize self-relocation under the situation of new media, achieve faster and more steady development in competition with new media represented by network media, and finally form a new situation of both competitive and integrated development between network media and traditional media in the era of new media.
\end{abstract}

Key words: era of new media, radio \& TV, network media, competition

\section{Introduction}

With rapid development of current internet technology, traditional media represented by radio \& TV are facing severe challenges. This is actually because powerful new media-network media have increasingly deepening and extensive influence, occupy more market shares with strong technical advantages and show incomparable development potential. Therefore, competition between radio \& TV and network media is inevitable. Then, does this mean that traditional media have completely lost market competitiveness? of course, the answer is negative. Radio \& TV media can also make full use of advanced information technology, create network sectors, have smoke-free market competition with network media, and make improvement constantly in competition, so as to complement each other's advantages with network media, achieve a win-win situation and form a situation of new media development in the era of new media.

\section{Advantages of radio \& TV media}

\subsection{More authoritative media information}

Compared with modern network media, one of the biggest advantages of radio \& TV media is that the information is of greater brand influence because of their upstream position in media industry. Traditional media such as newspapers and radio \& TV etc with regular sources of information and "gatekeepers" have higher authority and more loyal audience. That is to say, radio \& TV media have stronger credibility, which is an advantage that cannot be caught up with by network media in the short run as it is a media feature that radio \& TV media accumulate slowly over many years.

\subsection{More dominant media content}

With today's vigorous development of the internet, there are not many large-scale original network media. In 2014, a number of network media were affected by copyright issues. With today's increasingly strong consciousness of intellectual property protection 
and copyright protection, information services with formal copyright would be real core competitiveness of future media institutions including both traditional and network media. Over many years of operation, traditional media have a large number of professionally trained and very experienced creators and standardized working process, and have content advantage and production level that cannot be reached by new media. Although network media also try to make breakthroughs in terms of content originality, traditional media are still a preferred platform for massive production of excellent original content. Besides, for the sake of news control, China has a limited number of mainstream news network media such as People's Daily Online and Xinhua News etc that have right of gathering news, while portal websites have not been given such a right. However, news is a major information content that attracts the audience. Defects in content of network media caused by natural monopoly advantage of similar traditional media mean an unchangeable disadvantage.

\subsection{Better audio-visual experience effects}

Besides natural monopoly information content like news content, another type of information content is also a strong advantage of today's traditional media such as radio \& TV, i.e. live sports events. Although network media have been involved in live broadcast of music concerts, radio \& TV are undoubtedly the best media platforms for live broadcast of major sports events like the World Cup and Olympic Games. Audio-visual experience effects are another important factor besides professional expertise of network media practitioners that cannot reach practitioner standard of traditional media. Although relevant information can be received on mobile phones, tablet PCs and computers with respective advantages along with the development of mobile communication technology and internet technology, audience with high requirement of timeliness and audio-visual experience would still choose to watch sports events on traditional media like radio \& TV. That's why people would rather stay up late or even all night and watch live broadcast of the World Cup or Olympic Games in front of big-screen TVs, instead of watching rebroadcast on mobile phones or tablet PCs on the way to work the next morning.

\section{Characteristics of network media}

\subsection{Relevant definition}

Network media have a variety of definitions, such as the fourth media and new media. In a general sense, network media have characteristics including digital information, reliance on the internet, more advanced transmission channels and receiving terminals etc. Thus, we define network media as: an integrated information release platform that spreads digital data through the internet. Information is processed by a certain editing and production system and is received by different electronic terminals. Then, in China, network media mainly refer to electronic and online news release platforms etc sponsored by some portal websites and traditional news units, such as Sina and Sohu etc. It should be said that network media have experienced a gradually mature process of professional development, become gradually an integrated information release platform with strong political and technical characteristics, and have brought unprecedented severe test and huge challenges to the development of traditional media like radio \& TV with dominant advantages.

\subsection{Main characteristics}

Network media mainly rely on internet technology and thus have very fast transmission speed and network information update speed, which greatly enhance effectiveness and 
timeliness of information transmission. Network media provide a huge amount of information and rich content, but there is also a great deal of spam because of all for all communication. Moreover, due to a lack of "gatekeepers", network media haven't specially assigned people for information authenticity and effectiveness and thus couldn't enhance the authority. Even with rich content and a huge amount of information, traditional media including radio \& TV are still important sources of information of network media. With the development and popularization of mobile communication technology, convenience and economical efficiency of network media are reflected, and information forms of traditional media can be presented on network media terminals. In addition, interactivity and convenient participation of network media cannot be achieved by traditional media. On network media, information retrieve mainly relies on modern information technology and can be arbitrarily carried out by inputting key words, and network information can be collected through copy and paste functions. Besides, network media are multimedia-type new media that integrate various forms of media elements like text and pictures etc, breaking through constraints and limitations of traditional media. Network media are bound to be a main way of getting general information with the popularization of mobile terminals and decline of prices.

\section{Analysis of competition between radio $\&$ TV and network media under the situation of new media}

\subsection{Theoretical foundation}

In this era of the internet, the relationship between new and old media has been a hot topic. It is believed that the internet is the savior of traditional media. Regardless of what kind of views, the following theoretical perspectives are summarized in this paper. The first is the perspective of Jack Fuller who put forward the concept of "relative advantage". He compared between new and old media, and thought that: there was certain survival competition between both, and new media had advantages while old media were pushed to a relatively advantageous competitive field, so that both media could have relocation under coexistence of multimedia. Therefore, by analyzing from this perspective, network media are not perfect with both advantages and disadvantages as new media, and traditional media are also not good for nothing and have also advantages. Network media will not replace or eliminate traditional media, but only have more advanced and rapid development than traditional media and could realize interaction. Thus, traditional media return gradually to their advantageous fields. In a word, network media and traditional media have their respective advantages and disadvantages, coexist and develop in this era of new media.

The second is the perspective of Mcluhan, who believed that new media brought new media extension to human body and introduced the concept of "new scale". He thought that new media were new extension of human body and for which new media occurred. From this perspective, the occurrence and development of new media in social communication field are reasonable and legitimate, new media are a supplement extension and thus insufficiencies of old media are modified. However, this doesn't mean that network media like new media etc would replace radio \& TV and other traditional media, and network media only have multidimensional extension integrated with traditional media.

The third is the perspective of Roger Federer, who thinks that new media come gradually from morphological changes of old media instead of spontaneously or 
independently. The emergence of new media doesn't mean extinction of old media, but continuous evolution and adaptation instead. Therefore, traditional media represented by radio \& TV will not be replaced, and network media will gain rapid development, and both of them are mutually integrated, complementary, and harmoniously competitive.

\subsection{Integration in competition}

There is an inevitable competition between radio \& TV media and network media, after all both of them are products of different times. However, such competition is not about life and death, but about relocation and readjustment of market. The occurrence and development of network media will promote radio \& TV media to seek new development to cope actively with huge market impact from network media. Both types of media shall give full play to their advantages, have respective division of labor and market segment, and provide better information services. Traditional media shall make full use of and discover technical means and transmission concepts of new media, strive to develop network platforms based on advantages including rich content and authoritative information, not just put radio \& TV programs of traditional media simply on network platforms, but also really establish the concept of all media. By integrating traditional media program departments with network media departments, functions of network platform can be made full use of in case of events to release information timely through official microblog etc, so as to enhance timeliness and attract audience. Meanwhile, follow up subsequent and regular editorial work, launch program forecast through network platforms, and then broadcast in-depth reporting programs through traditional media platforms like radio \& TV, and collect in VOD system of network platforms for audience who need relevant information but have time conflict. This could overcome fleeting defect of radio \& TV information, and even achieve good data mining, provide users with recommended programs related to program information on demand, offer accurate information, save time of program information searching for users, increase users' rating time, and expand audience of traditional media. In this way, an all media three-dimensional information service mode can be really established for mass communication.

Network media shall make use of their advantages, provide services of mass-decentralized communication, offer latest information for users with characteristics of timeliness, convenience and information retrieval etc, have dislocation development with traditional media, and discover blank markets beyond mass communication mode of traditional media, instead of being merely an alternative of traditional media or repeated construction which results in a waste of resources. Network media with disadvantages in program content shall tend to have a recreational and fast information content service mode, while traditional media with mass communication shall tend to plough intensively and have a deeper, broader and thoughtful information content service mode.

Therefore, radio \& TV media and network media are both competitive and mutually integrated with respective advantages and characteristics, and both of them give play to their potential under the situation of new media to better adapt to modern media competition demand. There is an indivisibly and directly dependent relationship between network media and traditional media like radio \& TV etc, which is a concentrated reflection of further expansion of traditional media business and even an extension of traditional media to network platform. Traditional media can develop by use of advantages of network media. 
Similarly, network media could also apply advantages of traditional media to network, improve through modern technical means, give play to advantages of network, and truly achieve effective integration in competition with traditional media.

\section{Conclusions}

For media, mass means mainstream, and media accepted by most of people are mainstream social media. In content-based information transmission, traditional media are still mainstream and irreplaceable in a period of time, after all content advantage is unshakeable in the short run and the quality and authority of traditional media information will be the primary reason why such media are favored by the mass for a long period of time. New media, which focus on mass-decentralized communication, depend mutually on and develop jointly with traditional media. Both types of media are not mutually independent or exclusive, and have inevitably certain competition in market environment, but such competition is benign and sustainable. New and traditional media can be organically integrated under a competitive and coordinated mechanism, and achieve respective healthy development in social communication field, in order to better meet people's information demand.

\section{References:}

[1] Lu Fang. On Competition and Integration between Network Media and Traditional Media [J]. Journal of Social Science of Jiamusi University, 2005

[2] Jin Qing, Chen Peiai. Changes in News Media in the Internet Era [J]. Southeast Academic Research, 2001 (2)

[3] Wang Jian. Construct Network Media and Accelerate the Cooperation of Radio \& TV and Network [J]. China Cable Television Cable Wide-Angle, 2001

[4] Zhang Liqin. Integration and Combination, Coexistence and Co-prosperity-Development Direction of Traditional Media and Network Media Based on Mergence of Time Warner and AOL [J]. Chinese Journal of Journalism \& Communication, 2000 (2)

[5] Zhang Suhua et al. Competition and Integration between Network Media and Traditional Media [J]. Journal of Southern Institute of Metallurgy, 2005 